\title{
Hypothalamic-Pituitary Function in Depressive Illness: Insensitivity to Hypoglycaemia
}

\author{
B. J. CARROLL,* M.B., B.S., B.SC.
}

\begin{abstract}
ummary : The insulin tolerance test was performed in 116 severely depressed patients on admission to hospital and after treatment with electric convulsion therapy. The mean plasma cortisol response to hypoglycaemia was significantly impaired before treatment, particularly in the patients who also showed resistance to dexamethasone suppression. The results are consistent with hypothalamic-pituitary insensitivity to hypoglycaemia in these subjects.
\end{abstract}

\section{Introduction}

An abnormality of hypothalamic-pituitary-adrenal function has recently been described in depressive illness. Depressed patients were found to be unable to suppress their plasma levels of cortisol normally after receiving exogenous steroids, but normal suppression occurred on recovery (Butler and Besser, 1968 ; Carroll et al., 1968).

To further define hypothalamic-pituitary function in this illness the plasma cortisol response to insulin-induced hypoglycaemia has been investigated.

\section{Subjects and Methods}

Sixteen patients with severe depressive illness were studied. Their ages ranged from 42 to 77 , with a mean of 61 years. The criteria for inclusion in the study have been previously described (Carroll et al., 1968). All were treated with electric convulsion therapy and none received antidepressant drugs concurrently. Amylobarbitone was given as required for sedation.

The response to hypoglycaemia was measured by the standard insulin tolerance test (Greenwood et al., 1966), beginning at 8.30 a.m. and extending over 90 minutes. The criteria for responses to the insulin tolerance test which we have adopted are discussed in detail elsewhere (Carroll et al., 1969). A positive response when the blood sugar falls below $45 \mathrm{mg} . / 100 \mathrm{ml}$. is defined as a rise in plasma cortisol of greater than $5 \mu \mathrm{g}$./ $100 \mathrm{ml}$. together with a maximal level of at least $25 \mu \mathrm{g}$./ $100 \mathrm{ml}$. If only one of these criteria is satisfied the response is regarded as impaired. Failure to satisfy either criterion constitutes a negative response.

In 13 subjects the midnight dexamethasone suppression test was also performed on admission and after treatment (Carroll et al., 1968). An interval of at least two days occurred between this test and the insulin tolerance test.

Plasma cortisol was measured as total 11-hydroxycorticosteroids by the fluorometric method of Mattingly (1962). Blood sugar was measured by a ferro-ferricyanide method with an AutoAnalyzer (Technicon).

\section{Results}

The falls in blood sugar and the rises in plasma cortisol obtained during the insulin tolerance tests are summarized in Table I.

* N.H.M.R.C. Research Fellow, Department of Psychiatry, University of Melbourne, Clinical Sciences Building, Parkville, 3052, Victoria,
Australia.
Four negative responses and three impaired responses to hypoglycaemia were found in the depressed phase. In all these cases the minimum blood sugar was below $45 \mathrm{mg} . / 100 \mathrm{ml}$. No impaired or negative responses were seen in the recovered phase.

TABLE I.-Changes in Blood Sugar and Plasma Cortisol during Insulin Tolerance Test in 16 Depressed Patients on Admission and after Recovery

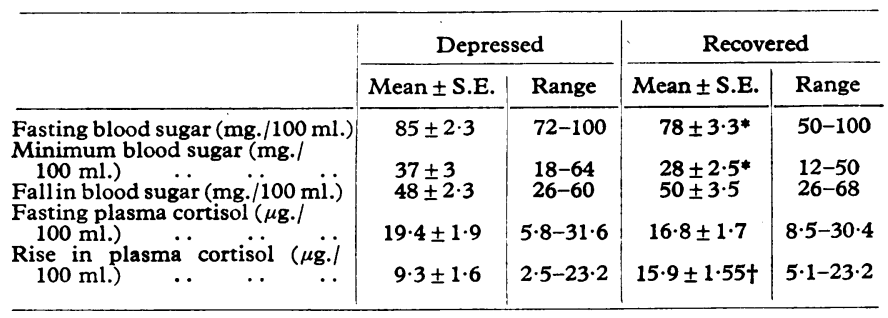

$* P<0.05$. $+P<0.01$.

The rise in plasma cortisol on recovery was significantly greater than the rise obtained while the subjects were depressed $(t=3.08, P<0.01)$. In 14 of the 16 cases the rise in cortisol was greater on recovery, and an analysis of variance of the plasma cortisol responses also supports this conclusion $(\mathrm{F}=$ 6.34, $P<0.03)$. The variation in response which is found between subjects does not account for the differences observed within subjects on repeating the test. Data for individual subjects are given in Table II.

TABLE II.-Individual Data for Minimum Blood Sugar, Plasma Cortisol Rise, and Post-dexamethasone 8.30 a.m. Plasma Cortisol Levels in Depressed $(D)$ and Recovered $(R)$ Phases

\begin{tabular}{|c|c|c|c|c|c|c|}
\hline \multirow{2}{*}{$\begin{array}{l}\text { Sub- } \\
\text { ject } \\
\text { No. }\end{array}$} & \multicolumn{2}{|c|}{$\begin{array}{l}\text { Minimum } \\
\text { Blood Sugar } \\
\text { (mg./100 ml.) }\end{array}$} & \multicolumn{2}{|c|}{$\begin{array}{l}\text { Plasma } \\
\text { Cortisol Rise } \\
(\mu \mathrm{g} . / 100 \mathrm{ml} .)\end{array}$} & \multicolumn{2}{|c|}{$\begin{array}{l}\text { Post-dexamethasone } \\
8.30 \text { a.m. Plasma } \\
\text { Cortisol }(\mu \mathrm{g} . / 100 \mathrm{ml} .)\end{array}$} \\
\hline & D & $\mathbf{R}$ & D & $\mathbf{R}$ & D & $\mathbf{R}$ \\
\hline $\begin{array}{r}1 \\
2 \\
3 \\
4 \\
5 \\
6 \\
7 \\
8 \\
9 \\
10 \\
11 \\
12 \\
13 \\
14 \\
15 \\
16\end{array}$ & $\begin{array}{l}28 \\
20 \\
64 \\
50 \\
32 \\
32 \\
48 \\
46 \\
44 \\
18 \\
32 \\
24 \\
30 \\
44 \\
42 \\
36\end{array}$ & $\begin{array}{l}12 \\
12 \\
50 \\
36 \\
32 \\
24 \\
26 \\
32 \\
44 \\
28 \\
28 \\
28 \\
22 \\
24 \\
20 \\
26\end{array}$ & $\begin{array}{r}15.4 \\
2.7 \\
5.6 \\
7.8 \\
11.1 \\
18.4 \\
16.5 \\
3.4 \\
9.7 \\
23.2 \\
8.4 \\
10.3 \\
7.2 \\
3.4 \\
2.5 \\
3.4\end{array}$ & $\begin{array}{r}19 \cdot 6 \\
20 \cdot 8 \\
9 \cdot 5 \\
21.5 \\
18.7 \\
21.5 \\
17 \cdot 8 \\
5 \cdot 1 \\
6 \cdot 4 \\
10 \cdot 2 \\
23 \cdot 2 \\
12.6 \\
12 \cdot 4 \\
19 \cdot 1 \\
21 \\
14.6\end{array}$ & $\begin{array}{l}18 \cdot 3 \\
26.8 \\
20 \cdot 8 \\
30 \\
17 \\
18 \cdot 8 \\
16 \\
27 \cdot 5 \\
8 \cdot 7 \\
1.5 \\
2.3 \\
2.9 \\
6.6 \\
= \\
=\end{array}$ & $\begin{array}{r}1.0 \\
3.4 \\
8.5 \\
8.6 \\
1.8 \\
0.5 \\
20.7 \\
25.8 \\
5.9 \\
2.6 \\
2.5 \\
3.2 \\
1.8 \\
= \\
-\end{array}$ \\
\hline
\end{tabular}

Subjects 1-6 showed reversible resistance to dexamethasone.

Subjects 7-8 remained resistant to dexamethasone after treatment. Subjects

In the depressed phase the patients had fasting blood sugar levels significantly higher than their levels on recovery, but the rate of fall in blood sugar and the absolute fall in blood sugar was similar on each occasion.

A significant correlation was found between the minimum blood sugar levels and the plasma cortisol rises in the recovery phase $(r=-0.546, P<0.02)$. In the depressed phase, however, the correlation was poor $(r=-0.366$, N.S.). 


\section{Relation to Dexamethasone Resistance}

Thirteen subjects received the 2-mg. midnight dexamethasone suppression test before and after treatment. In six cases no suppression occurred on admission, but a normal response to dexamethasone was found after treatment. There was no significant change in the response to dexamethasone of the remaining seven subjects.

For the whole group a significant negative correlation was found between the post-dexamethasone $8.30 \mathrm{a} . \mathrm{m}$. plasma cortisol levels and the rises in plasma cortisol during the insulin tolerance test $(\mathrm{r}=-0.5447, \mathrm{n}=26, \mathrm{P}<0.01)$. For the group showing reversible resistance to dexamethasone the correlation found was highly significant $(\mathrm{r}=-0.7813, \mathrm{n}=12, \mathrm{P}<0.001)$. No correlation was found for the group showing no change in their response to dexamethasone $(\mathrm{r}=-0.3476, \mathrm{n}=14, \mathrm{P}=$ N.S.) (see Chart). The six patients with reversible resistance to dexamethasone had a mean increase of $83 \%$ in response to the insulin tolerance test after treatment compared with their responses before treatment, while the other group had a mean increase of $11 \%$.

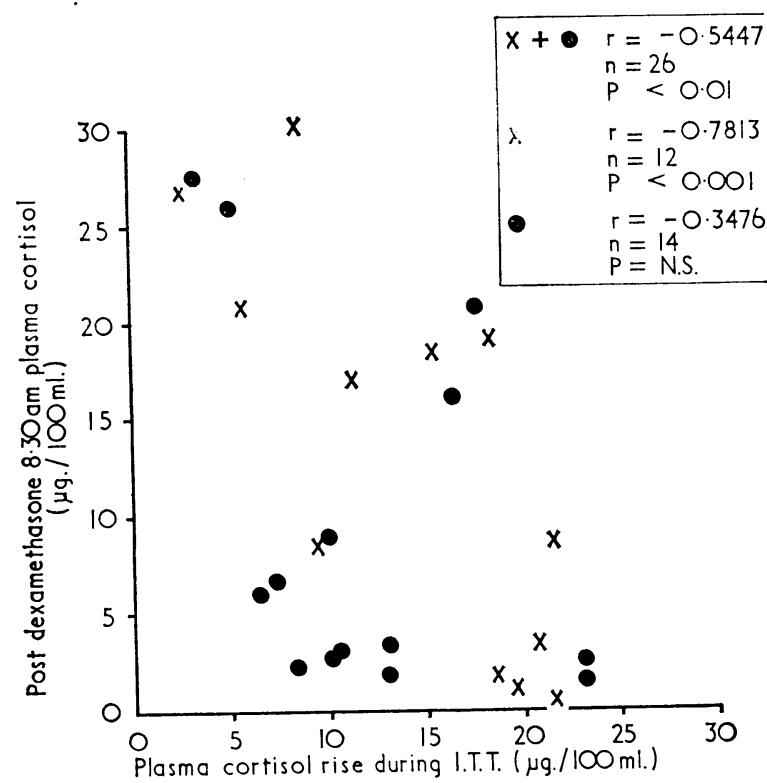

Relation between plasma cortisol rise during insulin tolerance test and post-dexamethasone 8.30 a.m. plasma cortisol levels. $\mathrm{X}=\mathrm{Group}$ showing reversible resistance to suppression by dexamethasone.

Analysis of Variance of Plasma Cortisol Rises:

$$
\begin{aligned}
& \text { SS Total }=1435.96 \text { with } 31 \text { D.F. } \\
& \text { SS Between subjects } \quad=276.59 \text { with } 15 \text { D.F } \\
& \text { SS Within subjects } \quad=1159.37 \text { with } 1 \text { D.F. } \\
& \text { SS Treatment } \quad=344.27 \text { with } 1 \text { D.F. } \\
& \text { SS Residual }=815.09 \text { with } 15 \text { D.F. } \\
& \mathrm{F}=6.335 . \quad \mathrm{P}<0.03 \text {. }
\end{aligned}
$$

\section{Discussion .}

The mean plasma cortisol response to hypoglycaemia was significantly greater on recovery than in the depressed phase. The responses found on recovery are in good agreement with those reported for normal subjects (Greenwood et al., 1966).
The greatest changes in response to hypoglycaemia occurred in the group who also showed a change in response to dexamethasone. Subjects with Cushing's syndrome are also known to be unresponsive to hypoglycaemia (Bethge et al., 1969 ; James et al., 1968).

The results are consistent with an impairment of hypothalamic-pituitary responsiveness to hypoglycaemia in some depressed patients associated with the previously described abnormality of feedback control (Carroll et al., 1968). Other explanations of the results are possible and are briefly considered.

The raised basal levels of plasma cortisol indicate that adrenal insensitivity to adrenocorticotrophic hormone (A.C.T.H.) is not present in the depressed phase. This has been confirmed in depressed patients by finding normal responses to A.C.T.H. infusions and no significant change after treatment (Carroll and Martin, in preparation). Inhibition of A.C.T.H. release by amylobarbitone during the depressed phase may be considered. There is good experimental evidence, however, that the plasma cortisol response to hypoglycaemia is not affected by barbiturates, at least in the cat (Kreiger ct al., 1968). The last dose of amylobarbitone was given 12 hours before beginning the insulin tolerance test. All the patients received similar amounts of amylobarbitone on the nights before each test, so that the difference between the two subgroups described is unlikely to be a drug artifact.

The degree of hypoglycaemia was greater in the recovered phase. The mean minimum blood sugar $(37 \mathrm{mg} . / 100 \mathrm{ml}$.) in the depressed phase was nevertheless well below the level of $45 \mathrm{mg} . / 100 \mathrm{ml}$. regarded as necessary to stimulate an adrenocortical response in normal subjects (Greenwood et al., 1966). The omission of the results of four patients whose blood sugar levels did not fall below $45 \mathrm{mg}$. $/ 100 \mathrm{ml}$. when depressed does not affect the result: a significant difference between the plasma cortisol responses is found for the remaining 12 subjects $(t=$ $2 \cdot 88, \mathrm{P}<0.02$ ).

None of these possibilities appears to be adequate to account for the results obtained. The association of change in sensitivity to hypoglycaemia with change in sensitivity to dexamethasone suggests that the impaired plasma cortisol responses to hypoglycaemia may be due to reversible hypothalamicpituitary dysfunction in these patients.

It is a pleasure to thank Dr. F. I. R. Martin and Dr. R. Melick for helpful advice and discussion and Professor B. M. Davies for supporting this work. The blood sugar estimations were generously provided by Dr. Cameron Baird. Thanks are also extended to Messrs. Geigy Pharmaceuticals for financial assistance.

\section{REFERENCES}

Bethge, H. Baycr, J. M., and Wink-lmann, W. (1969). Acta Endocrinologica, 60, 47 .

Butler P. W. P and Besser G. M (1968). Lancet, 1, 1234.

Carroll, B. J., Martin, F. I. R., and Davies, B. (1968). British Medical Fournal, 3, 285 .

Carroll, B. J., Pearson, M. J., and Martin, F. I. R. (1969). Metabolism. In press.

Greenwood, F. C., Landon, J., and Stamp, T. C. B. (1966). Fournal of Clinical Investigation, 45, 429.

James, V. H. T., Landon, J., Wynn, V., and Greenwood, F. C. (1968). fournal of Endocrinology, 40, 15.

Krieger, D. T., Silverberg, A. I., Rizzo, F., and Krieger, H. P. (1968) American fournal of Physiology, 215, 959.

Mattingly, D. (1962). Journal of Clinical Pathology, 15, 374. 